\title{
Spatial pattern of dengue cases: An analysis in Bangi District, Selangor, Malaysia
}

\author{
Nuriah Abd Majid, ${ }^{1}$ Ruslan Rainis, ${ }^{2}$ Mazrura Sahani, ${ }^{3}$ Ahmad Fariz Mohamed, ${ }^{1}$ \\ Sarah Aziz Abdul Ghani Aziz, ${ }^{1}$ Nurafiqah Muhamad Nazi ${ }^{1}$ \\ ${ }^{1}$ Institute for Environment and Development (LESTARI), Universiti Kebangsaan Malaysia, Bangi, Selangor \\ Darul Ehsan; ${ }^{2}$ School of Humanities, Universiti Sains Malaysia, Minden, Pulau Pinang; ${ }^{3}$ Faculty of Health \\ Sciences, Universiti Kebangsaan Malaysia, Kuala Lumpur, Malaysia
}

\begin{abstract}
In recent decades, dengue outbreaks have become increasingly common around the developing countries, including Malaysia. Thus, it is essential for rural as well as urbanised livelihood to understand the distribution pattern of this infection. The objective of this study is to determine the trend of dengue cases reported from the year 2014 to 2018 and the spatial pattern for this spread. Spatial statistical analyses conducted found that the distribution pattern and spatial mean centre for dengue cases were clustered in the eastern part of the Bangi region. Directional distribution observed that the elongated polygon of dengue cluster stretched from the Northeast to the Southwest of Bangi District. The standard distance observed for dengue cases was smallest in the year $2014(0.017 \mathrm{~m})$, and largest in $2016(0.019 \mathrm{~m})$, whereas in the year 2015, 2017 and 2018, it measured $0.018 \mathrm{~m}$. The average nearest neighbour analysis also displayed clustered patterns for dengue cases in the Bangi District. The three spatial statistical analyses (spatial mean centre, standard distance and directional distribution) findings illustrate that the dengue cases from the year 2014
\end{abstract}

Correspondence: Nuriah Abd Majid, Institute for Environment and Development (LESTARI), Universiti Kebangsaan Malaysia, Bangi 43600, Selangor Darul Ehsan, Malaysia.

E-mail: nuriah@ukm.edu.my

Key words: Dengue fever; standard distance; mean spatial centre; directional distribution; Malaysia.

Acknowledgements and funding: this study was funded by a grant number (GGPM-2018-030) research project of Universiti Kebangsaan Malaysia. Thanks to the Ministry of Health Malaysia and Meteorological Department Malaysia for the data provided.

Received for publication: 3 July 2020.

Revision received: 22 January 2021.

Accepted for publication: 22 January 2021.

(C) Copyright: the Author(s), 2021

Licensee PAGEPress, Italy

Geospatial Health 2021; 16:915

doi:10.4081/gh.2021.915

This article is distributed under the terms of the Creative Commons Attribution Noncommercial License (CC BY-NC 4.0) which permits any noncommercial use, distribution, and reproduction in any medium, provided the original author(s) and source are credited. to 2018 are clustered in the Northeast to the Southwest of the study region.

\section{Introduction}

Dengue fever is one of the world's most deadly mosquitoborne viral diseases caused by a few closely related dengue virus types. According to World Health Organisation (WHO) there were about 1.2 million cases of dengue fever around the world in 2008, which then rose to 3.34 million in 2016 (WHO, 2020), while the Malaysia Ministry of Health Dengue (2019) has stated that the number of cases is high in Malaysia and neighbouring tropical countries, for instance Cambodia, China, Laos, Singapore, Vietnam, as well as in Australia, The Philippines and the Pacific Islands. In Malaysia, dengue is predominantly an urban disease, and Selangor is the area that has been primarily affected by the disease with high numbers of cases reported (Khormi et al., 2011). The tropical and subtropical climate enriched with high precipitation, humidity and temperature lead to a longer vector lifespan and stronger reproduction (Aziz et al., 2014; Das et al., 2014; Nik Syaza Lina et al., 2017).

The Aedes aegypti mosquito is the primary vector of dengue, and the virus is transmitted to every individual the infected female bites during its lifespan. Human-made containers with water are favourite breeding places for Ae. aegypti (WHO, 2020). Hot and humid climates with an average temperature of $27^{\circ} \mathrm{C}$ provide suitable conditions for the mosquito to produce, especially in urban areas. The spread of dengue is also linked to the weather and the season. Most studies in Malaysia have identified the association between dengue and rainfall distribution (Aziz et al., 2014; Rohani et al., 2014; Williams et al., 2015; Mohiddin et al., 2015; Hii et al., 2016; Masnita et al., 2018). Stagnant water after rainfall enlarge the Ae. aegypti breeding grounds. However, there is a decline in dengue cases when heavy rains continue in a city as they destroy the mosquito larvae in exposed containers (Mohiddin et al., 2015). Land surface and water temperatures in agricultural are higher than in forested areas, which can accelerate the growth process of Ae aegypti larvae but these conditions reduce the life cycle of adult mosquitoes (Kweka et al., 2016). However, an increase in temperature above $28^{\circ} \mathrm{C}$ results in a decline of dengue cases as the water reservoir dries up and thus impedes the breeding possibilities. Besides, a study done by Rohani et al. (2014), found that the Aedes mosquitoes also need a neutral $\mathrm{pH}$ to reproduce. A recent survey conducted by Ahmad et al. (2018) shows that the number of these mosquitoes also decreases during the haze, a seasonal air pollution in many Southeast Asian countries caused by 
underground smoldering peat fires, which interferes with mosquito reproduction. The smoke and heat carried by the haze can also make it difficult for the mosquito to detect human body heat but this is a contended issue with researchers arguing that the spread of dengue is not affected by the haze (Thiruchelvam et al., 2018).

For many years, the government has conducted programmes and activities to control and overcome the dengue outbreaks in Malaysia. However, with increasing population densities dengue will be a significant health risk. Therefore, viral disease mapping and monitoring using geographical information systems (GIS) have become vital for epidemic control and further management plan strategies. Spatial analysis by means of commercially available software (ESRI, 2018) help to estimate the risk for dengue fever across affected areas and offer insights into the nature of disease clusters. This study aims to determine and analyze the trend of dengue fever cases and its spatial spread in Bangi, Selangor, taking into account selected weather variables, such as rainfall and temperature. This study aims to provide valuable information for effective control and decision-making with regard to dengue outbreaks. GIS software ArcGIS v. 10.5 (ESRI, Redlands, CA, USA) was used to investigate and visualise the distribution pattern in a geographic context (Abdul Samad and Shaharudin, 2017). Three spatial statistical methods, directional distribution, spatial mean centre and standard distant analysis, were used to test the temporal trends of dengue cases for the period 2014 to 2018. The findings should enhance public health surveillance with respect to dengue and contribute to preparation of future management plans.

\section{Materials and methods}

\section{Study area}

This study area was located $38 \mathrm{~km}$ south of Kuala Lumpur in Bangi Town, Hulu Langat District, Malaysia with coordinates of $2^{\circ} 55^{\prime} 20.6$ 'N and 101 ${ }^{\circ} 46^{\prime} 50.6$ 'E (Figure 1). This region in the southern part of Hulu Langat hosts a new town and converted townships erected during the latest four decades. Bangi is an emerging land development area for housing estates covering 2243 hectares, with steadily increasing numbers of the population and economic activity. The average temperature is $27^{\circ} \mathrm{C}$, with an annual average rainfall of $2302 \mathrm{~mm}$ making Bangi a potential area for the spread of dengue, something which needs to be controlled to reduce the vulnerability of urban populations (Mutheneni et al., 2016).

\section{Data}

A complete dataset of dengue fever cases was obtained from the Hulu Langat District Health Office. The dataset is based on register records at the government hospital in Bangi covering the period 2014-2018. It includes 7779 positive dengue cases recorded for Bangi Town during these five years. It contains information on the residences of the patients and was used to map the distribution of the cases in ArcMap v. 10.5 (ESRI).

\section{Statistical analysis}

\section{Spatial mean centre}

The mean center is the point with the shortest average distance from all other points, and is explained by the average $\mathrm{x}$ and $\mathrm{y}$ values for the input feature centroids. This tool requires projected data to accurately measure distances. Here, the average of the coordinates of all patients in the study constituted the spatial mean centre in the study area. The mean centre is a visualisation of the distribution based on the distribution of dengue cases, which changes along with addition or subtraction of cases. It is calculated by the equations below:

$$
\begin{aligned}
& \bar{X}=\frac{\sum_{i=1}^{n} x_{i}}{n} \\
& \bar{Y}=\frac{\sum_{i=1}^{n} y_{i}}{n}
\end{aligned}
$$

where $x_{i}$ and $y_{i}$ are the geographical coordinates of case $i$, and $n$ is equal to the total number of cases.

\section{Standard distance}

The standard distance is the single value that measures the compactness of the distribution around the mean centre. It is a value that can be shown on a map by drawing a circle with a radius equal to the standard distance. Distance standards are a new class of property forming a circular polygon centred on the mean centre for each case. The value attributes for each polygon of the circle are the $\mathrm{x}$-coordinate, the $\mathrm{y}$-coordinate of the different centre means and the standard distance (the radius).

Standard distance calculation is as follows:

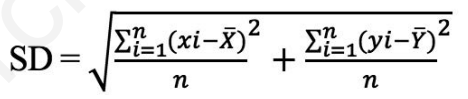

where $x_{i}$ and $y_{i}$ are the geographical coordinates of case $i,\left(x^{-} y^{-}\right)$ represents the mean centre of the cases, and $n$ is equal to the total number of cases.

\section{Standard deviational ellipse}

The standard deviational ellipse (SDE) creates an output feature class containing elliptical polygons, one for each case, which show the standard deviation of the $\mathrm{x}$-coordinates and $\mathrm{y}$-coordinates from the mean center giving the central tendency, dispersion and trend direction. The usual way to measure patterns in the area is a set of standards that calculates the distances on the $\mathrm{x}$ and $\mathrm{y}$ axes. These measures defines the axis of the ellipse distribution characteristics, whose particular orientations are shown by the ellipse's elongated features. Disease surveillance studies use ellipses to model spatial distribution since the central tendency and dispersion are two principal aspects, particularly to epidemiologists (Eryando et al., 2012). The ArcGIS v. 10.5 software used to conduct these spatial statistical analyses were the following:

$\operatorname{SDE} x=\sqrt{\frac{\sum_{i=1}^{n}\left(x_{i}-\bar{X}\right)^{2}}{n}}$

$\mathrm{SDE} y=\sqrt{\frac{\sum_{i=1}^{n}\left(y_{i}-\bar{Y}\right)}{n}}$

where $x_{i}$ and $y_{i}$ are the coordinates of case $i,\left(\bar{x}, y^{-}\right)$represents the mean centre of the cases, and $n$ is equal to the total number of cases. 


\section{Spatial pattern analysis}

In addition to the spatial distribution analysis, the distances between the locations of each incidence points were also analysed by using the average nearest neighbour (ANN), which is calculated as the observed average distance divided by the expected average distance (Abd Majid et al., 2019). When the ratio is $<1$, the data display a clustered pattern and when the ratio is $>1$, there is instead a dispersed pattern. This analysis was applied to evaluate whether the dengue incidence in the study area clustered, random or dispersed (Abd Majid et al., 2016).

\section{Results}

The result shows that the study area had 1240 dengue cases in 2014, which climbed to 1968 cases in 2015. In 2016, the number declined to 1407 cases; however, it rose again to 1687 cases in 2017 and then finally went down to 791 cases in 2018 . There was thus a strong downturn of reported dengue cases compared to the previous years.

The spatial mean centre was used to analyse the foci of the phenomena recorded. Table 1 shows the variation of the geographical coordinates during the study period, and Figure 2 shows the location of every dengue fever case for the period 2014-2018, together with their mean respective centres calculated annually based on the monthly record of the number of cases.

Figure 3 shows the directional distribution of dengue cases for six years, respectively. The ellipse polygons of dengue cases were very similar in all six years, with the general distribution direction stretching from Northeast to the Southwest of the Bangi Town (Figure 3). The long axis direction of the ellipse polygons varied by $12.22^{\circ}, 8.89^{\circ}, 1.58^{\circ}, 15.36^{\circ}$ and $15.07^{\circ}$ for the years 2014 to 2018 , respectively. For 2015, the ellipse polygon was found to be lower and smaller on the upper side of the polygon compared to 2014 and extended further towards the South of the study area, while the one for 2016 had a larger radius to the West of Bangi Town. However, the ellipse polygon for 2017 was much more elongated in the northern direction than any of the other ones and

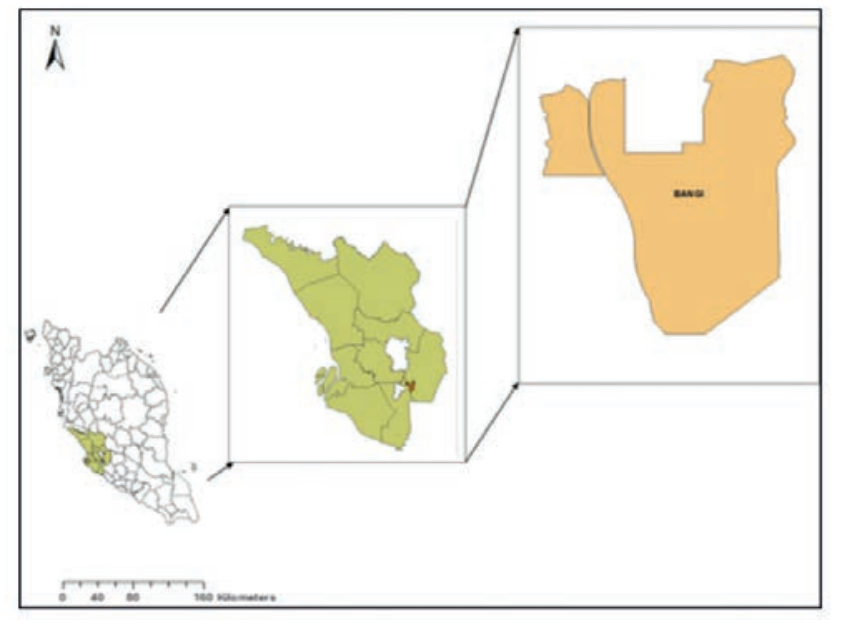

Figure 1. Study site. it was also more narrow. In contrast, the 2018 ellipse polygon had a stronger presence to the Southwest.

Figure 4 shows the standard distance with regard to dengue fever cases in the Bangi District. The standard distances for dengue cases reported for 2014 and 2017 were $0.017 \mathrm{~m} 0.019 \mathrm{~m}$, respectively, which was the smallest and the largest in the range for all the years, while it was the same $(0.018 \mathrm{~m})$ for 2015,2017 and 2018. This means that the distribution was of similar density for all the years investigated.

Table 2 and Figure 5 show that that the spatial pattern of the dengue fever cases for each year of the study period was aggregated with a nearest neighbour ratio $<1$ at a critical value (z-score) less than -2.58 and a significance level (P-value) of 0 , suggesting a less than $1 \%$ likelihood that this clustered pattern could be random (ESRI, 2018). Thus, the outcome of the ANN calculations indicated that the dengue hotspots were located in the north-east-

Table 1. Variation of the geographical coordinates for the spatial mean centre 2014-2018.

\begin{tabular}{lcc} 
Year & $\mathrm{x}$-coordinate & $\mathrm{y}$-coordinate \\
2014 & 101.774471 & 2.960287 \\
2015 & 101.775198 & 2.955823 \\
\hline 2016 & 101.772130 & 2.955496 \\
2017 & 101.774598 & 2.964154 \\
\hline 2016 & 101.771081 & 2.956525 \\
\hline
\end{tabular}

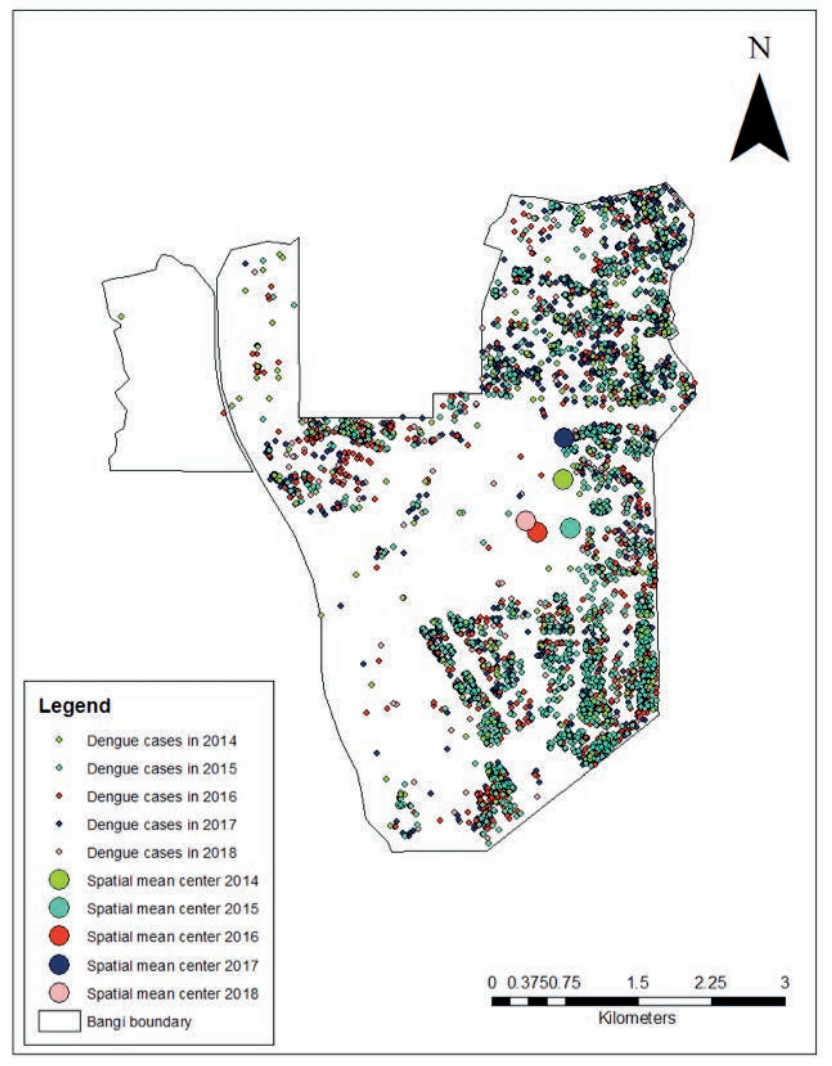

Figure 2. Variation of the spatial mean centre of dengue cases in Bangi Town in the period 2014-2018. 
ern, eastern, southern part of the study area, with a smaller cluster in the West (Figure 2).

\section{Discussion}

It is essential to understand the epidemic spatio-temporal pattern of the dengue outbreak and the geographic distribution measures provide this through the formulation of the spatial mean centre, directional distribution and standard distance. The statistical analysis undertaken was used to determine the spatial distribution of dengue fever in Bangi and to get a better understanding of the underlying causes that might be associated with the cases. Something must have caused the clustered pattern seen in Figure 2 and it seems highly likely that the rapid growth of the population density in Bangi Town contributed to the high dengue incidence noted in the study period.

The spatial statistical analysis performed in this study found that dengue cases reported throughout the study period clustered around an area ranging from Northeast to Southwest covering almost half the study site. With all likelihood these same areas are also preferred breeding sites of the dengue Ae aegypti vector. Perhaps more importantly is that the urban areas in the Klang Valley that we studied has seen a rapid increase in population in the last few years and now reached saturation levels barring any further expansion. Growth of new urban areas such as Bandar Baru Bangi, and the modern industrial sectors such as Sg. Chua, Kajang, Cheras Batu 9, Cheras Batu 11 and Balakong around Bangi Town have contributed to the increase in population. Although rapid population growth is often related to an increased dengue incidence in urban settings due to the presence of artificial dengue vector breeding sites, this factor is not directly related to Bandar Baru Bangi Town (Rozilawati et al., 2015). The proximity to the capital city of Kuala Lumpur and the central city Putrajaya has also made it a prime area for homes, as it is good for commuting by public transport with existing useful road systems (Shaharudin et al., 2002).

GIS application in this study has shown that this approach is not only useful for investigation of dengue outbreaks, but may also be applied for the surveillance of various communicable diseases by linking disease occurrence, cause identification and the geography of the area affected. Basic information and this type of linkages should assist regulatory decision making and actions applied to the target area. Research also could be broadened to cover other aspects such as land use, socioeconomic situation, and even a study of the effectiveness of preventive measures.

Table 2. Analysis by average nearest neighbour for dengue cases reported from 2014 to 2018.

\begin{tabular}{lccc} 
Year & Ratio & Z-score & P-value \\
2014 & 0.128988 & -58.889254 & 0.000000 \\
2015 & 0.359938 & -54.320747 & 0.000000 \\
\hline 2016 & 0.375227 & -44.833228 & 0.000000 \\
2017 & 0.399819 & -47.159633 & 0.000000 \\
\hline 2018 & 0.396804 & -32.454686 & 0.000000 \\
\hline
\end{tabular}

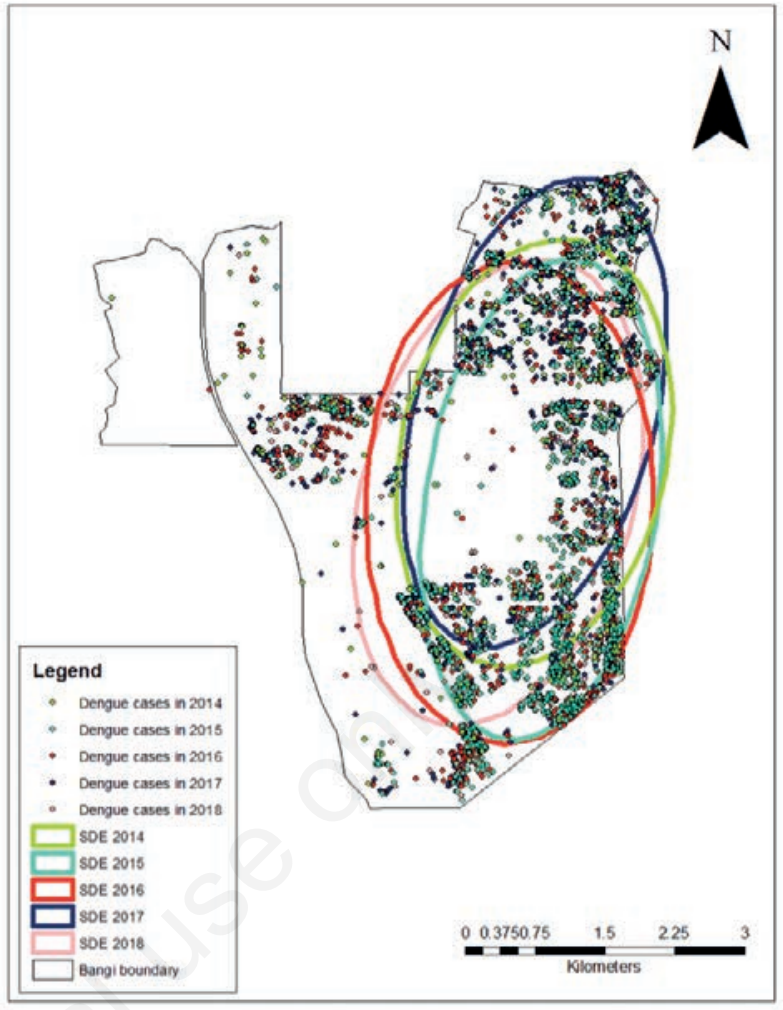

Figure 3. Standard deviational ellipses (SDE) polygons of dengue cases in Bangi Town in the period 2014-2018.

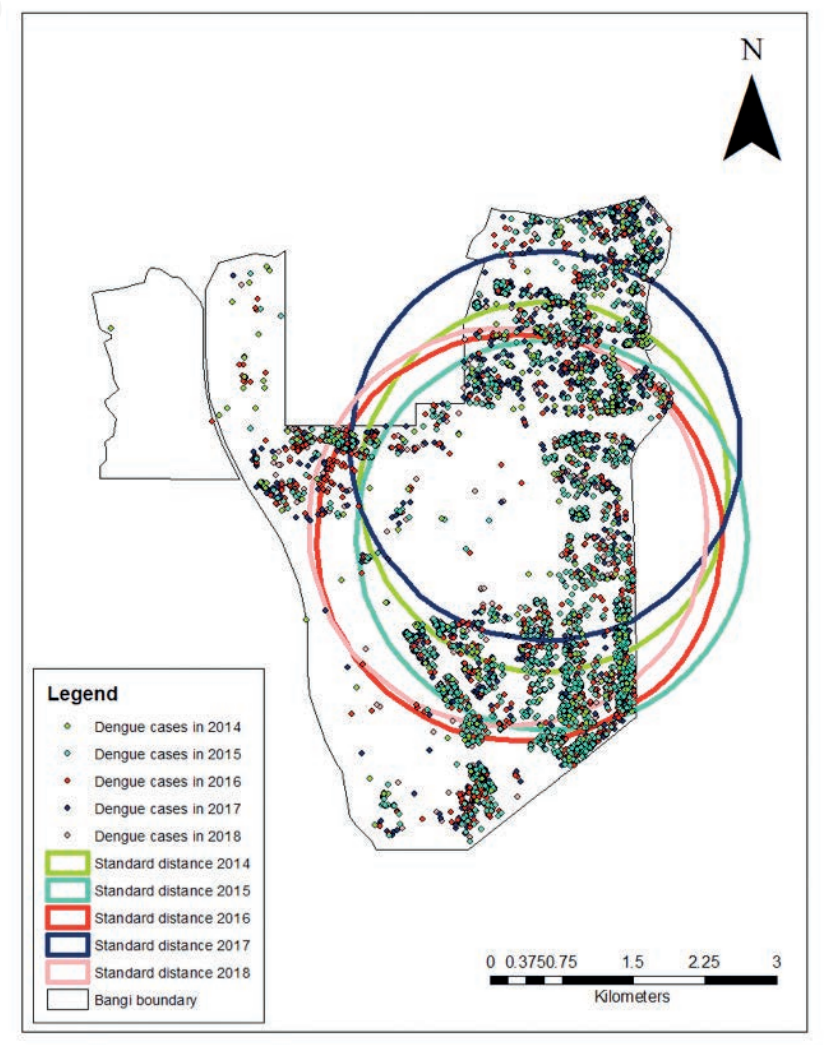

Figure 4. Standard distance for dengue cases in Bangi District for the period 2014-2018. 
A

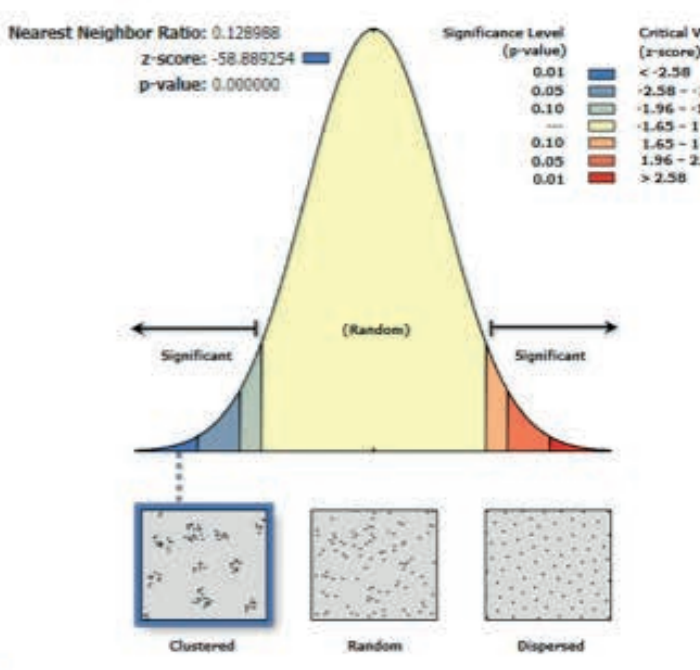

C

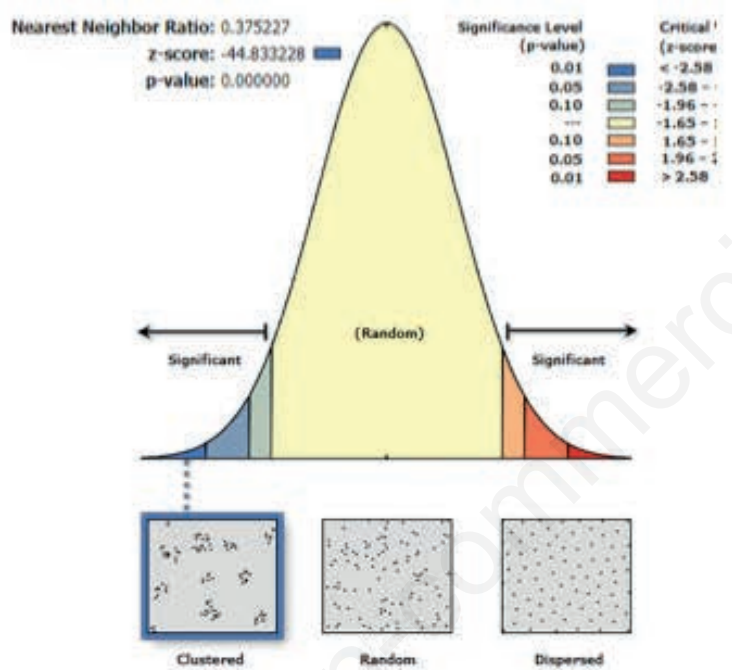

E

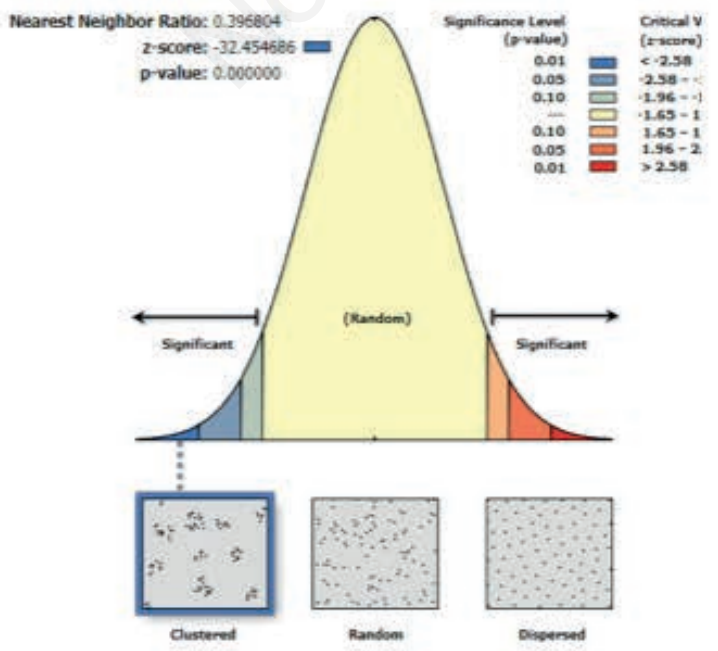

B

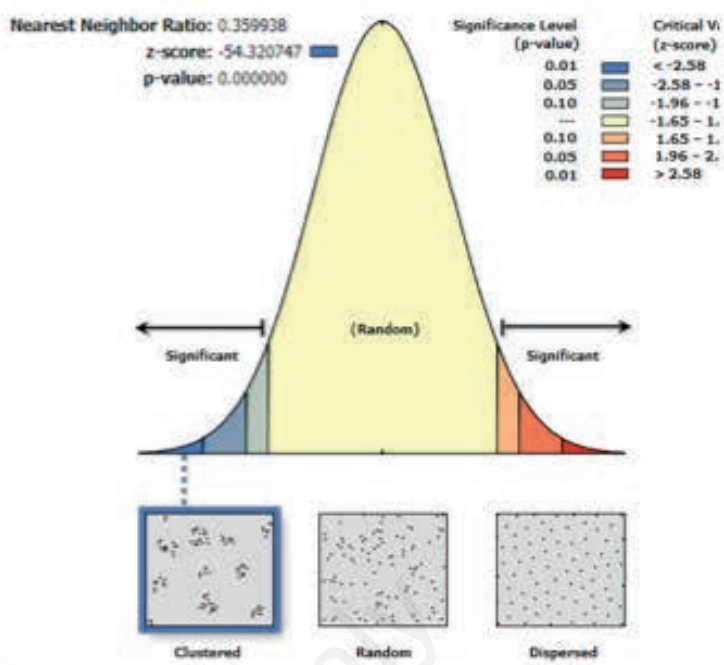

D

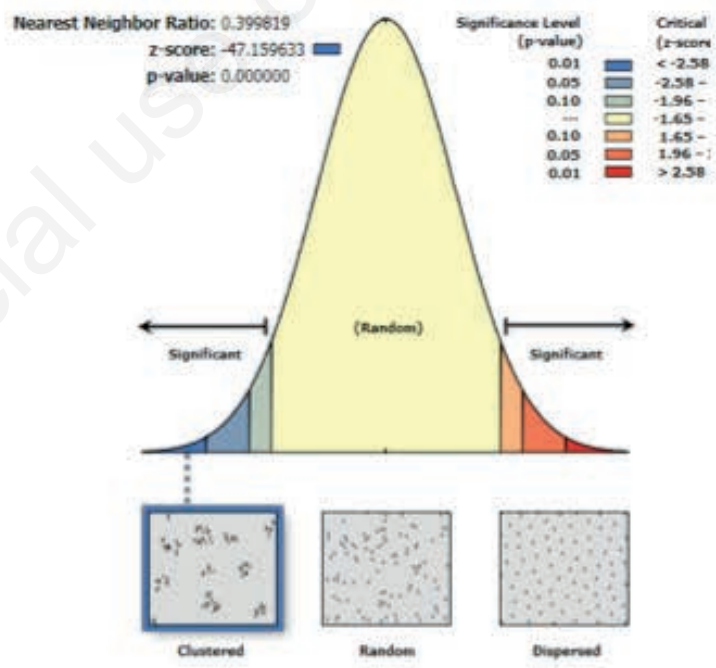

Figure 5. Average nearest neighbour analysis for dengue cases: A) year 2014; B) year 2015; C) year 2016; D) year 2017 ; E) year 2018. 
Geospat Health 6:77-84.

\section{Conclusions}

Spatial statistics play a significant role in understanding the epidemiology of dengue. This approach contributed to illustrate the clustering of this infection along a trajectory stretching from Northeast to Southwest in Bangi District in the 2014-2018 period. Hence, the formation of clustered patterns can assist responsible organisations to focus on identified hotspots as they signify the presence of frequent dengue cases. Together with the community living in the hotspot areas, authorities may stimulate mitigation actions to eliminate breeding sites of Aedes mosquitoes that would eventually improve community resilience and decrease the magnitude of hotspots in targeted areas.

\section{References}

Abd Majid N, Muhamad Nazi N, Mohamed AF, 2019. Distribution and spatial pattern analysis on dengue cases in Seremban District, Negeri Sembilan, Malaysia. Sustainability 11:3572.

Abd Majid N, Rainis R, Muhiyuddin WM, 2016. [Analisis Taburan dan Corak Ruangan Pelbagai Jenis Kegagalan Cerun di Pulau Pinang, Malaysia]. Int $J$ Environ Soc Space 4:1-15. [in Malaysian].

Abdul Samad H, Shaharudin I, 2017. The emerging Kuala Lumpur extended mega urban region (KLEMUR): implications on urban prosperity in Malaysia. Int J Malay World Civilis 5:67-74.

Ahmad R, Suzilah I, Wan Najdah WMA, Topek O, Mustafakamal I, Lee HL, 2018. Factors determining dengue outbreak in Malaysia. PLoS One 13:e0193326.

Aziz S, Aidil, RM, Nisfariza MN, Ngui R, Lim YAL, Wan Yusoff WS, Ruslan R, 2014. Spatial density of Aedes distribution in urban areas: a case study of breteau index in Kuala Lumpur, Malaysia. J Vector Borne 51:91-6.

Das M, Gopalakrishnan R, Kumar D, Gayan J, Baruah I, Veer V, Dutta P, 2014. Spatiotemporal distribution of dengue vectors \& identification of high risk zones in district Sonitpur, Assam, India. Indian J Med Res 140:278-84.

Eryando T, Susanna D, Pratiwi D, Nugraha, F, 2012. Standard deviational ellipse (SDE) models for malaria surveillance, case study: Sukabumi district-Indonesia, in 2012. Malar J 11:P130.

ESRI, 2018. An overview of the spatial statistics toolbox. Available from: https://desktop.arcgis.com/en/arcmap/10.3/ tools/spatial-statistics-toolbox/an-overview-of-the-spatialstatistics-toolbox.htm Accessed: 21 January 2021.

Hii YL, Zaki RA, Aghamohammadi N, Rocklöv J, 2016. Research on climate and Dengue in Malaysia: a systematic review. Curr Environ Health Rep 3:81-90.

Khormi HM, Kumar L, Elzahrany RA, 2011. Modeling spatiotemporal risk changes in the incidence of dengue fever in Saudi Arabia: a geographical information system case study.
Kweka EJ, Kimaro EE, Munga S, 2016. Effect of deforestation and land use changes on mosquito productivity and development in Western Kenya Highlands: implication for malaria risk. Front Public Health 26:238.

Malaysia Ministry of Health, 2019. History and epidemiology of dengue. Available from: http://denggi.myhealth.gov.my/history-and-epidemiology-of-dengue/?lang=en Accessed: 19 January 2021.

Masnita MY, Nazri CD, Rodziah I, Ariza Z, 2018. Assessing the temporal distribution of dengue vectors mosquitoes and its relationship with weather variables. Serangga 23:112-25.

Mohiddin A, Jaal Z, Md-Lasim A, Dieng H, Zuharah WF, 2015. Assessing dengue outbreak areas using vector surveillance in north east district, Penang Island, Malaysia. Asian Pac J Trop Dis 5:869-76.

Mutheneni SR, Mopuri R, Naish S, Gunti D, Upadhyayula SM, 2016. Spatial distribution and cluster analysis of dengue using self-organising maps in Andhra Pradesh, India, 2011-2013. Parasite Epidemiol Control 4:52-61.

Nik Syaza Lina NR, Haliza AR, 2017. The association between climatic factors and dengue fever: a study in Subang Jaya and Sepang, Selangor. Malaysian J Public Health Med 1:140-50.

Rohani A, Aidil Azahary AR, Malinda M, Zurainee MN, Rozilawati H, Wan Najdah WMA, Lee HL, 2014. Eco-virological survey of Aedes mosquito larvae in selected dengue outbreak areas in Malaysian J Vector Borne Dis 51:327-32.

Rozilawati H, Tanaselvi K, Nazni WA, Mohd Masri S, Zairi J, Adanan CR, Lee HL, 2015. Surveillance of Aedes albopictus Skuse breeding preference in selected dengue outbreak localities, peninsular malaysia. Trop Biomed 32:49-64.

Shaharudin I, Shamsul AS, Tahir A, Mariam M, Azah D, Nik Shamsidah NI, 2002. [Sistem maklumat geografi (GIS) dan sektor kesihatan awam: kajian demam denggi di Bandar Baru Bangi dan Kajang]. Jurnal Kesihatan Masyarakat 8:34-42. [in Malaysian].

Thiruchelvam L, Dass SC, Zaki R, Yahya A, Asirvadam VS, 2018. Correlation analysis of air pollutant index levels and dengue cases across five different zones in Selangor, Malaysia. Geospat Health 13:613.

WHO (World Health Organisation), 2020. Dengue and severe dengue. World Health Organisation, Geneva, Switzerland. Available from: https:/www.who.int/news-room/factsheets/detail/dengue-and-severe-dengue Accessed: 19 January 2021.

Williams CR, Gill BS, Mincham G, Mohd Zaki AH, Abdullah N, Mahiyuddin WRW, Ahmad R, Shahar MK, Harley D, Viennet E, Azil A, Kamaluddin A, 2015. Testing the impact of virus importation rates and future climate change on dengue activity in Malaysia using a mechanistic entomology and disease model. Epidemiol Infect 143:2856-64. 